\title{
OPEN High performance silicon electrode enabled by titanicone coating
}

\author{
Zahilia Cabán Huertas ${ }^{1,2}$, Daniel Settipani ${ }^{1}$, Cristina Flox ${ }^{1}$, Joan Ramon Morante ${ }^{2,3}$, \\ Tanja Kallio ${ }^{1 \bowtie}$ \& Jordi Jacas Biendicho ${ }^{2 \bowtie}$
}

This paper presents the electrochemical performance and characterization of nano Si electrodes coated with titanicone (TiGL) as an anode for Li ion batteries (LIBs). Atomic layer deposition (ALD) of the metal combined with the molecular layer deposition (MLD) of the organic precursor is used to prepare coated electrodes at different temperatures with improved performance compared to the uncoated Si electrode. Coated electrodes prepared at $150^{\circ} \mathrm{C}$ deliver the highest capacity and best current response of $1800 \mathrm{mAh} \mathrm{g}^{-1}$ at $0.1 \mathrm{C}$ and $150 \mathrm{mAh} \mathrm{g}^{-1}$ at $20 \mathrm{C}$. This represented a substantial improvement compared to the Si baseline which delivers a capacity of $1100 \mathrm{mAh} \mathrm{g}^{-1}$ at $0.1 \mathrm{C}$ but fails to deliver capacity at $20 \mathrm{C}$. Moreover, the optimized coated electrode shows an outstanding capacity of $1200 \mathrm{mAh} \mathrm{g}^{-1}$ at $1 \mathrm{C}$ for 350 cycles with a capacity retention of $93 \%$. The improved discharge capacity, electrode efficiencies, rate capability and electrochemical stability for the Si-based electrode presented in this manuscript are directly correlated to the optimized TiGL coating layer deposited by the ALD/MLD processes, which enhances lithium kinetics and electronic conductivity as demonstrated by equivalent circuit analysis of low frequency impedance data and conductivity measurements. The coating strategy also stabilizes SEI film formation with better Coulombic efficiencies (CE) and improves long cycling stability by reducing capacity lost.

The demands for developing advanced energy storage devices have dramatically increased during the past decade. One reason for this is that our society is living a communication revolution; another important motive is the implementation of the electric vehicle in a decarbonized society. Due to the environmental issues affecting our planet, more efficient energy storage technologies are needed. Therefore, batteries will play an important role in the new renewable energy based smart grid development and off the grid applications. The development of high energy density and fast charge/discharge lithium batteries requires new materials. Commercial batteries use graphite and layered oxides with cell energy densities up to $300 \mathrm{Wh} \mathrm{kg}^{-11}$ which are lower than the requirements claimed for having a competitive autonomy in an electric battery based mobility ${ }^{2}$.

Silicon is a promising material as a negative electrode for LIBs. It can store almost $4 \mathrm{~mol}$ of Li per mol of $\mathrm{Si}$ $\left(\mathrm{Li}_{15} \mathrm{Si}_{4}\right)$ leading to a theoretical volumetric capacity of $2190 \mathrm{mAh} \mathrm{L}{ }^{-13}$ which is higher than the graphite one i.e. $837 \mathrm{mAh} \mathrm{L}^{-14}$. Additionally, Si has a low discharge potential of $0.05 \mathrm{~V} \mathrm{vs.} \mathrm{Li} / \mathrm{Li}^{+5}$ and it is an abundant element on the Earth's crust; its low cost and the well-developed manufacturing infrastructure make this material a promising candidate for high energy (next generation) LIBs. However, there are some complications during silicon performance. It exhibits a large volume expansion upon $\mathrm{Li}$ insertion and removal of approximately $300 \%$ of its original size ${ }^{6}$ which leads to severe electrode degradation, loss of electric contact and continuous side-effect reactions and, eventually, to an increased cell resistance, low rate-capability and a low Coulombic efficiency (CE) ${ }^{7}$. Different approaches have been proposed to overcome silicon limitations ${ }^{8}$. For instance, the use of nanoparticles with a critical particle diameter below $150 \mathrm{~nm}$ to reduce particle cracking upon first lithiation ${ }^{9}$, formulation of new and effective binder compositions to better compensate for the volume expansion of the silicon ${ }^{10}$, synthesis of silicon nanostructures e.g. core-shell ${ }^{11}$, nanowires ${ }^{12}$ or nanotubes ${ }^{13}$, with improved performance compared to micro-scale powders, and fabrication of composite materials with carbon to account for the volumetric changes while preserving electrical contact ${ }^{14}$. Alternatively, silicon can also be prelitiated $\left(\mathrm{Li}_{\mathrm{x}} \mathrm{Si}_{\mathrm{y}}\right)$ to avoid its large volume expansion on initial cycles but these phases appear to be highly unstable at room temperature ${ }^{15}$.

A more practical and rational way to mitigate the aforementioned issues that have impeded a performant $\mathrm{Si}$ electrode is based on surface modifications by using ALD combined with the more powerful MLD. By combining these two techniques, the substrate is exposed to metal and organic precursors that go through a self-limiting reaction resulting in the deposition of a hybrid inorganic-organic film known as metalocone. MLD yield a coating with a lot of attractive properties such as precise structure and thickness control and conformal high aspect

\footnotetext{
${ }^{1}$ Aalto University, Kemistintie 1, 02150 Espoo, Finland. ${ }^{2}$ Catalonia Institute for Energy Research, Jardins de les Dones de Negre 1, $2^{\text {a }}$ p., 08930 Barcelona, Spain. ${ }^{3}$ Faculty of Physics, University of Barcelona, Marti I Franques, 1, 08028 Barcelona, Spain. ${ }^{\circledR}$ email: tanja.kallio@aalto.fi; jjacas@irec.cat
} 
ratio structures. Recent studies conducted by Abdulagatov et al. demonstrate that combining $\mathrm{TiCl}_{4}$-glycerol (GL) results in a film with improved mechanical properties compared to $\mathrm{TiCl}_{4}$-ethylene glycol (EG) ${ }^{16,17}$. This approach can be used to produce flexible coatings to control the chemical reactivity and volume expansion of silicon; an example is alucone coating which provides significant improvements in cycling stability, rate capability, and CE for nano-Si composite electrodes ${ }^{18}$ up to $2000 \mathrm{mAh} \mathrm{g}^{-1}$ at $0.05 \mathrm{C}$. Other interesting example is the use of zincone which improves discharge capacity to $1741 \mathrm{mAh} \mathrm{g}^{-1}$ at $2000 \mathrm{mAg}^{-1}$ and that is related to the formation of a stable LiF-rich SEI layer for the coated sample ${ }^{19}$.

However, MLD has one main disadvantage associated with the homo-bifunctional reaction sequence between precursors and a surface which limits the number of active surface sites. Thus, the double reactions hinder the growth of the thin layers. The use of glycerol eliminates this problem since it is a homo-trifunctional precursor ${ }^{20}$. Glycerol characteristics will lead to more bridging between the polymer chains. MLD requirements for the precursors are sufficient vapor pressure, reactivity, and stability at the reaction temperature to ensure feasible film growth $^{21}$. Many organic precursors exhibit low vapor pressures at room temperature, and it is thus mandatory to heat them to achieve a sufficient precursor supply. Therefore, finding organic compounds which would fulfill the requirements for MLD reaction is not simple ${ }^{22}$.

The use of Ti-based coatings to enhance the performance of Si electrodes has already been discussed by others ${ }^{23-25}$. A recent example is the use of $\mathrm{TiO}_{2}$ as amorphous layer to encapsulate $\mathrm{Si}$ particles delivering high capacity of $2804 \mathrm{mAh} \mathrm{g}^{-1}$ at $1 \mathrm{Ag}^{-1}$ for the first cycle. This improvement was attributed to the hollow core-shell nanostructure of the material ${ }^{23}$. Additionally, Ti coating enhances the electrical conductivity of Si electrodes for samples prepared by electron beam physical vapor technique ${ }^{24}$. Also titanicone has been used to enhance the electrochemical performance of N-CNTs towards Li storage ${ }^{25}$.

Consequently, our purpose is to develop a titanicone coating to modify the surface of Si and improve, in turn, the electrochemical performance of the anode for LIBs. The optimized deposition process of titanicone using ALD/MLD techniques described in this paper opens attractive options for more advantageous commercialization of Si-based electrodes.

\section{Results}

Silicon powder from Alfa Aesar was first characterized to check its purity and particle size/morphology (Fig. 1). The XRD pattern shows a high-purity sample since all diffraction peaks correspond to silicon with a cubic crystal structure (S.G.: Fd-3 m) and $a=3.867(1)$ A (Fig. 1a). A SEM image (Fig. 1b), shows particles of spherical shape with a diameter in the range of $40-145 \mathrm{~nm}$, see histogram inset. The analysis shows that $50 \%$ of the particles have a diameter around $60 \mathrm{~nm}$ considering the diameter of 101 particles. The size and morphology of silicon particles was also investigated by TEM (Fig. 1c), which confirmed a homogenous distribution of nanoparticles. EDX spectrum (Fig. 1d), shows oxygen corresponding to the native oxide layer covering the nanoparticles while the $\mathrm{C}$ signal is related to substrate used for the SEM analysis.

Si electrodes fabricated using a doctor blade were used as substrates for titanicone coating. ALD/MLD growth on a substrate typically depends on the deposition temperature, and hence it was optimized first. For this study, the number of cycles during titanicone deposition was fixed to 100 cycles, based on previous publications ${ }^{26}$. Temperatures $130^{\circ} \mathrm{C}, 150^{\circ} \mathrm{C}, 170^{\circ} \mathrm{C}, 190^{\circ} \mathrm{C}$, and $210^{\circ} \mathrm{C}$ were selected to carry out the deposition of TiGL on the Si electrode, table S1, and FTIR spectroscopy was first used to evaluate structure of the composite electrodes. Figure 2 shows the results obtained by FTIR and the corresponding analysis. The FTIR spectra recorded for the uncoated electrode (Si baseline) do not display any particular feature. However, coated electrodes (Si TiGL) show characteristic peaks of carbon and titanium vibrations. $\mathrm{CH}_{2}$ stretches originating from the glycerol molecule can be observed at wavenumbers $2928 \mathrm{~cm}^{-1}$ and $2870 \mathrm{~cm}^{-1}$, together with a more negligible absorption at $1248 \mathrm{~cm}^{-1}$. Other peaks associated with the GL molecules are C-C and C-O absorptions at $1135 \mathrm{~cm}^{-1}$ and $1086 \mathrm{~cm}^{-1}$. At low wavenumbers, vibration modes related to the Ti-O bonds are also present. More specifically, the $820 \mathrm{~cm}^{-1}$ sharp peaks are assigned to the Ti-O stretch mode. In the range $720-550 \mathrm{~cm}^{-1}$, absorptions bands are related to $\mathrm{Ti}-\mathrm{O}-\mathrm{Ti}$ bonds. The combination of both the carbon related groups and the Ti absorptions provides evidence of the successful deposition of a hybrid organic-inorganic film containing Ti and GL at temperatures $130{ }^{\circ} \mathrm{C}$, $150^{\circ} \mathrm{C}, 170^{\circ} \mathrm{C}$, and $190^{\circ} \mathrm{C}$. That is not the case for the sample prepared at $210^{\circ} \mathrm{C}$, which shows a decrease of the intensity for the associated FTIR peaks compared to the lower deposition temperatures used, especially those related to GL. According to previous reports ${ }^{27}$, high temperature applied to the MLD process does not yield high-quality thin films since the number of reactive sites and reaction mechanism is affected.

Coated electrodes were then characterized by SEM/EDX as presented in Figure S1 in Supporting Information for Si TiGL 150. Samples Si TiGL 130, 150, 170, and 190 showed a homogeneous distribution of titanium with no changes on the particle morphology with respect to the Si baseline. Also, there were no differences between diffraction patterns collected before and after coating (Fig. S2). Peaks were identified as Si and Cu, the last corresponding to the current collector. $\mathrm{Cu}$ peaks were index as $\mathrm{F} \mathrm{m}-3 \mathrm{~m}(225)$.

The electrochemical properties of the electrodes were evaluated in half-cells using different electrochemical tests. Electrodes were first activated at $0.03 \mathrm{C}$. Figure $3 \mathrm{a}, \mathrm{b}$ show the activation profile (cycle 1 ) and characteristic charge/discharge curves for Si baseline and Si TiGL 150, respectively, as black 0.03 C, red 0.10 C and blue 0.20 $\mathrm{C}$ lines. Electrodes show typical charge/discharge profiles associated to Si reduction/oxidation with a low $\mathrm{CE}$ during the activation cycle (black lines) indicating that lithium is consumed from the electrolyte in irreversible reactions suggesting SEI formation. Si baseline shows the lowest CE in agreement with reported results for nanosized powders ${ }^{28,29}$ while for certain coated samples CE is significantly improved, for instance CE for Si TiGL 150 is $86 \%$ and $84 \%$ for Si TiGL 190 for cycle 2 activation, see Table S2 (Supporting Information) SI. This indicates sample coating reduces side reactions and promotes the formation of a more stable SEI film. After activation, 

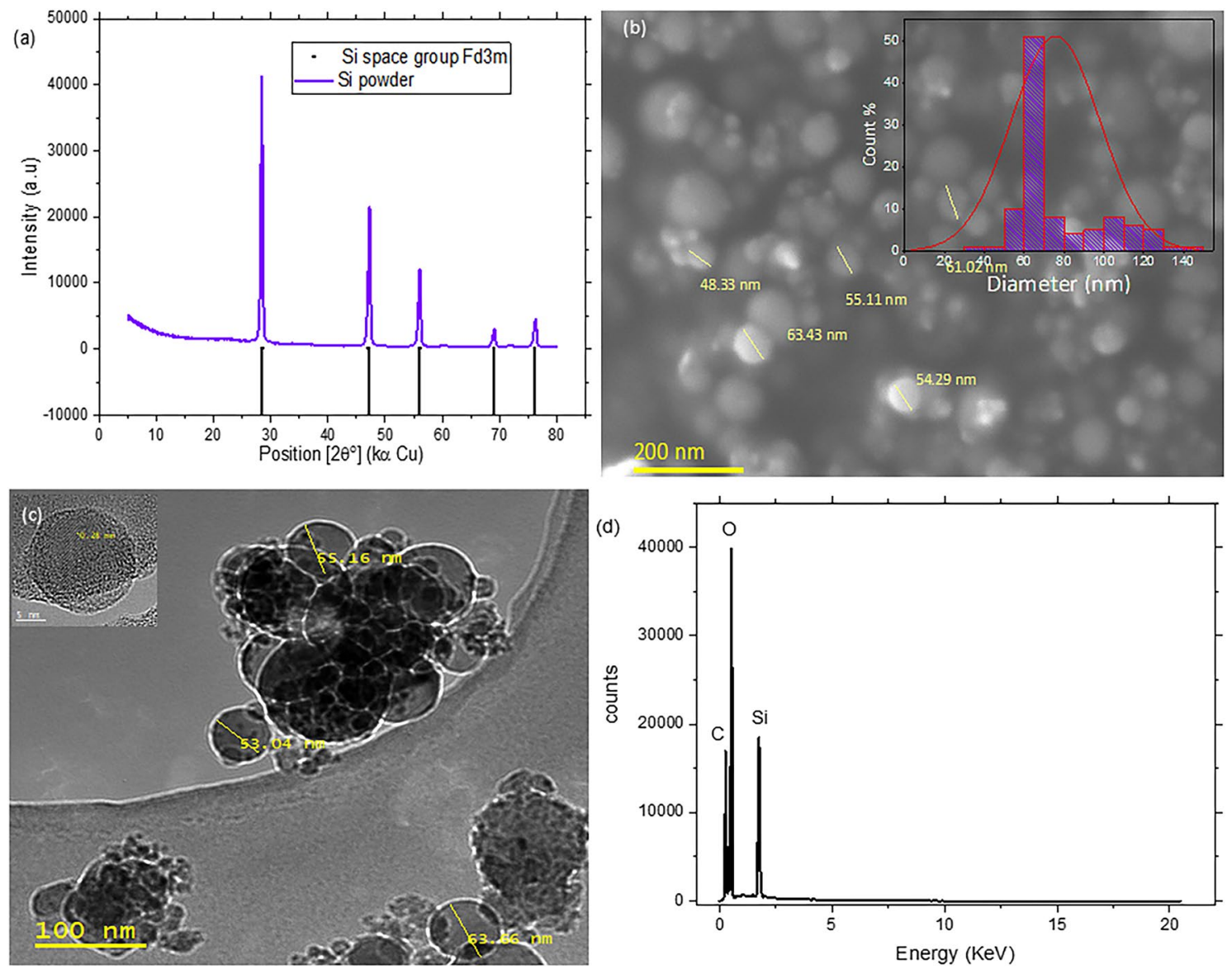

Figure 1. Structure, particle size/morphology and composition for the silicon (a) XRD pattern measured using Cu radiation, (b) a SEM image and histogram inset showing particle size distribution, (c) a TEM image and (d) EDX spectra.

the CE of the Si electrode at $0.1 \mathrm{C}$ is 57\% and Si TiGL 150, 170 and 190 show the highest efficiency among the samples in the range of $95 \%$.

For rate capability tests, results are shown in Fig. 3c,d for Si baseline and Si TiGL 150. Si baseline shows discharge capacities of $1100,800,550,400,300$ and $200 \mathrm{mAh} \mathrm{g}^{-1}$ at $0.1,0.2,0.5,1,2$ and $5 \mathrm{C}$, respectively. At higher C-rates of $1020 \mathrm{C}$, the electrode fails to deliver any significant capacity. On the other hand, Si TiGL 150 delivers high (and stable) discharge capacities: 1800, 1600, 1400, 1100, 800, $500 \mathrm{mAh} \mathrm{g}^{-1}$ at 0.1, 0.2, 0.5, 1, 2 and $5 \mathrm{C}$, respectively, which are in the range of best performing Si electrode materials reported up to date $\mathrm{e}^{30,31}$. The performance at $10 \mathrm{C}$ and $20 \mathrm{C}$ rates is also significant delivering 300 and $150 \mathrm{mAh} \mathrm{g}^{-1}$, respectively. For these several C-rates tested, the CEs are always close to $100 \%$ indicating no side reactions at the electrodes. Results from Si TiGL 150 are best performing ones among all coated samples.

Figure 4a shows a comparison between the Si TiGL samples as a function of C-rate. Si TiGL 130 shows similar performance to Si baseline and Si TiGL 170, 190 and 210 deliver lower capacities than Si TiGL 150 at all $\mathrm{C}$-rates tested. From this, we can consider that synthesis conditions for titanicone coating on Si electrode should be adjusted to $150{ }^{\circ} \mathrm{C}$ using $\mathrm{TiCl}_{4}$ and glycerol as precursor and reactant, respectively, during the ALD/MLD deposition process. As for this deposition temperature, the electrode shows an enhanced kinetic performance which affords high capacity at C-rates up to $20 \mathrm{C}$. To further evaluate the performance of Si TiGL 150, a long-term cycling tests at $1 \mathrm{C}$ up to 350 cycles was performed for this selected coated sample and Si baseline and results are presented in Fig. 4b. Discharge capacity for Si baseline is in the range of reported Si based electrodes using nano-scale powders ${ }^{32}$ delivering $400 \mathrm{mAh} \mathrm{g}^{-1}$ on initial cycling and then the capacity decreases in a step-wise manner down to $250 \mathrm{mAh} \mathrm{g}^{-1}$ with a capacity retention of $53 \%$. Besides, Si TiGL 150 delivers a stable capacity of $1180 \mathrm{mAh} \mathrm{g}^{-1}$ with a $94 \%$ capacity retention up to cycle 350 . Similar stability has been reported for alucone coating $^{18}$. The enhanced performance was attributed to a better structural integrity of the coated electrode compared to bare silicon, preserving intimate contact between carbon and active particles upon lithiation, as evidenced by post-mortem studies ${ }^{18}$.

To get further insights into the kinetics of the Si TiGL electrodes, EIS and 4-point conductivity measurements were conducted on the selected samples. Figure S3 shows the current vs voltage plots for a Si wafer coated with TiGL (as reference), Si baseline and Si TiGL 150, respectively. The conductivity of the Si wafer coated with TiGL is $0.055 \mathrm{~S} \mathrm{~cm}^{-1}$, and conductivities of Si baseline and $\mathrm{Si} \mathrm{TiGL} 150$ are $0.00155 \mathrm{~S} \mathrm{~cm}^{-1}$ and $0.00799 \mathrm{~S} \mathrm{~cm}^{-1}$. So the electrical conductivity is increased for the Si TiGL 150 electrode. 


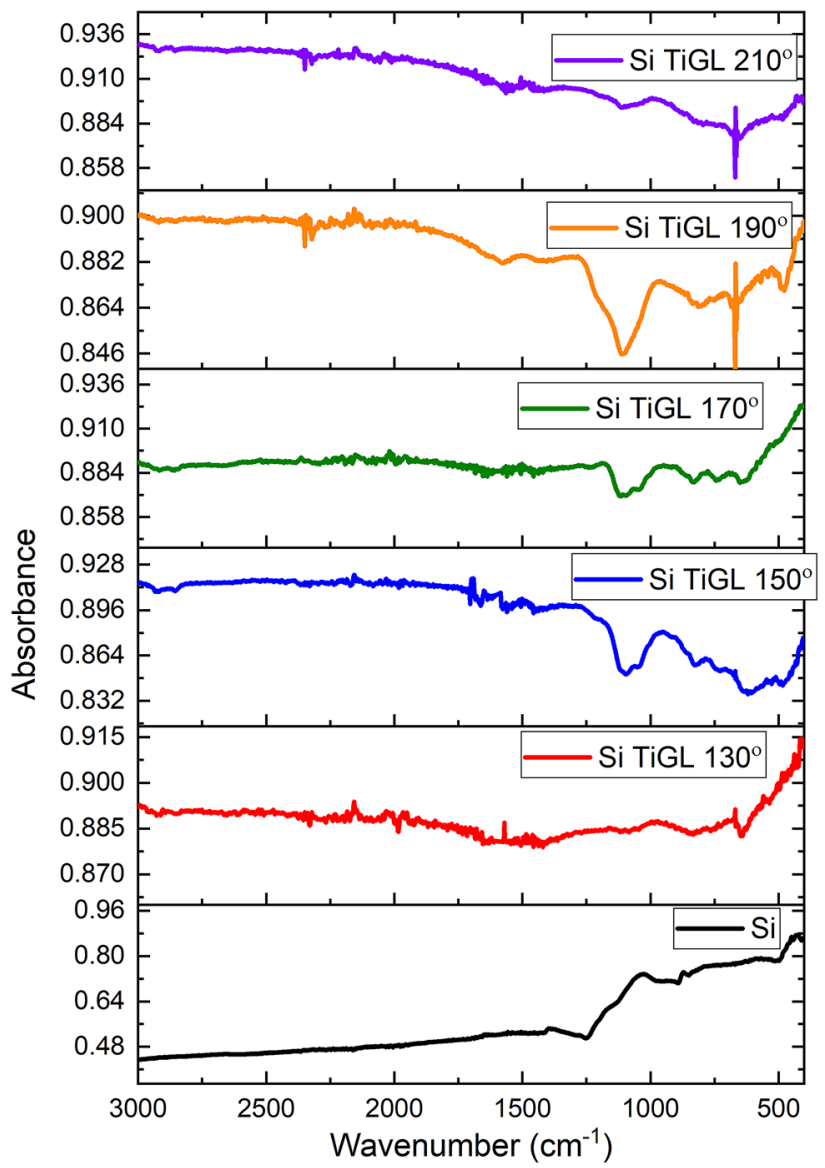

Figure 2. FTIR spectra of Si baseline and Si TiGL 130, 150, 170, 190 and 210 samples.

Figure 5a shows Nyquist plots, b shows $Z^{\prime}$ vs $\omega^{-0.5}$ plots and fitting results for c shows Si baseline and d Si TiGL 150 using the equivalent circuit inset. Impedance plots presented in the form of $Z^{\prime}$ vs - Z" (Fig. 5a), are characterized by a non-ideal semicircle at high frequency and a low frequency tail. The shape and slope of the tail is related to a frequency range where the kinetics of the system are almost entirely limited by the rate of the chemical diffusion process in the host material. The capacitance associated to each sample semicircle is in the range of $20 \mu \mathrm{F}$ but their charge-transfer resistance $\left(\mathrm{R}_{\mathrm{CT}}\right)$ varies slightly being $100 \Omega$ for Si baseline and $30 \Omega$ for $\mathrm{Si}$ TiGL 150. Low frequency data presented in the form of $Z^{\prime}$ vs $\omega^{-0.5}$ (Fig. 5b), show straight lines corresponding to $\mathrm{R}_{\mathrm{CT}}$ and Warburg element in series, inset. The $\mathrm{Z}^{\prime}$ axis intercept is $\mathrm{R}_{\mathrm{CT}}$ and the slope (or Warburg coefficient $\sigma)$ is related to the diffusion coefficient of lithium ions. The linear fit indicates that lithium-ion kinetics is significantly enhanced for Si TiGL $150(\sigma=58)$ compared to Si baseline $(\sigma=500)$ in agreement with the C-rate tests presented in Fig. 3c,d. A more detailed analysis was conducted by equivalent circuit fitting in order to extract the chemical diffusion coefficient $\left(D_{\mathrm{Li}+}\right)$ of the electrodes. Figure $5 \mathrm{c}$, d show impedance data measured at $50 \%$ SOC after the sample activation, and equivalent circuit for the fitting inset. The fitting results for both samples are presented in Table S3. The use of the Constant Phase Element (CPE) in parallel to the $\mathrm{R}_{\mathrm{CT}}$ was motivated by the non-ideal response of the high-frequency semicircle together with a Warburg open (Wo) circuit element in series to the $\mathrm{R}_{\mathrm{CT}}-\mathrm{CPE}$ circuit. Fits to the impedance data were satisfactory leading to low error \% for the circuit elements used. Calculated $D_{\mathrm{Li}+}$ from fitted Wo- $\mathrm{T}^{33}$ indicate that lithium diffusivity is enhanced by four orders of magnitude; from $2.21 \times 10^{-12} \mathrm{~cm}^{2} \mathrm{~s}^{-1}$ to $1.15 \times 10^{-8} \mathrm{~cm}^{2} \mathrm{~s}^{-1}$ for Si baseline and Si TiGL 150, respectively. This is in good agreement with Fig. 4 showing an improved C-rate performance for the coated electrode. Indeed, diffusivity values herein presented are in good agreement to the reported ones for nano-silicon powder calculated by CV, GITT and EIS techniques and in the range of $10^{-12} \mathrm{~cm}^{2} \mathrm{~s}^{-134}$. The improved performance of Si TiGL 150 delivering high discharge capacity $1200 \mathrm{mAh} \mathrm{g}^{-1}$ at $1 \mathrm{C}$ and $500 \mathrm{mAh} \mathrm{g}^{-1}$ at $5 \mathrm{C}$ is correlated to the enhanced electrode kinetics by titanicone coating. Electrochemical results for the optimized coated electrode are comparable to $\mathrm{Si}$ nanowires ${ }^{35}$ or nanotubes ${ }^{36}$ with Li diffusivities in the same order of magnitude e.g. $10^{-8} \mathrm{~cm}^{2} \mathrm{~s}^{-1}$.

\section{Discussion}

TiGL coating provides an improvement in the performance of the nano-Si electrode as a negative electrode for LIBs. The performed analyses reveal that the optimum temperature to deposit TiGL over the silicon electrode is $150{ }^{\circ} \mathrm{C}$, using 100 deposition cycles. These are optimized deposition parameters for the combined ALD/ MLD process, an emergent technology to build next-generation batteries. Indeed, deposition techniques are 

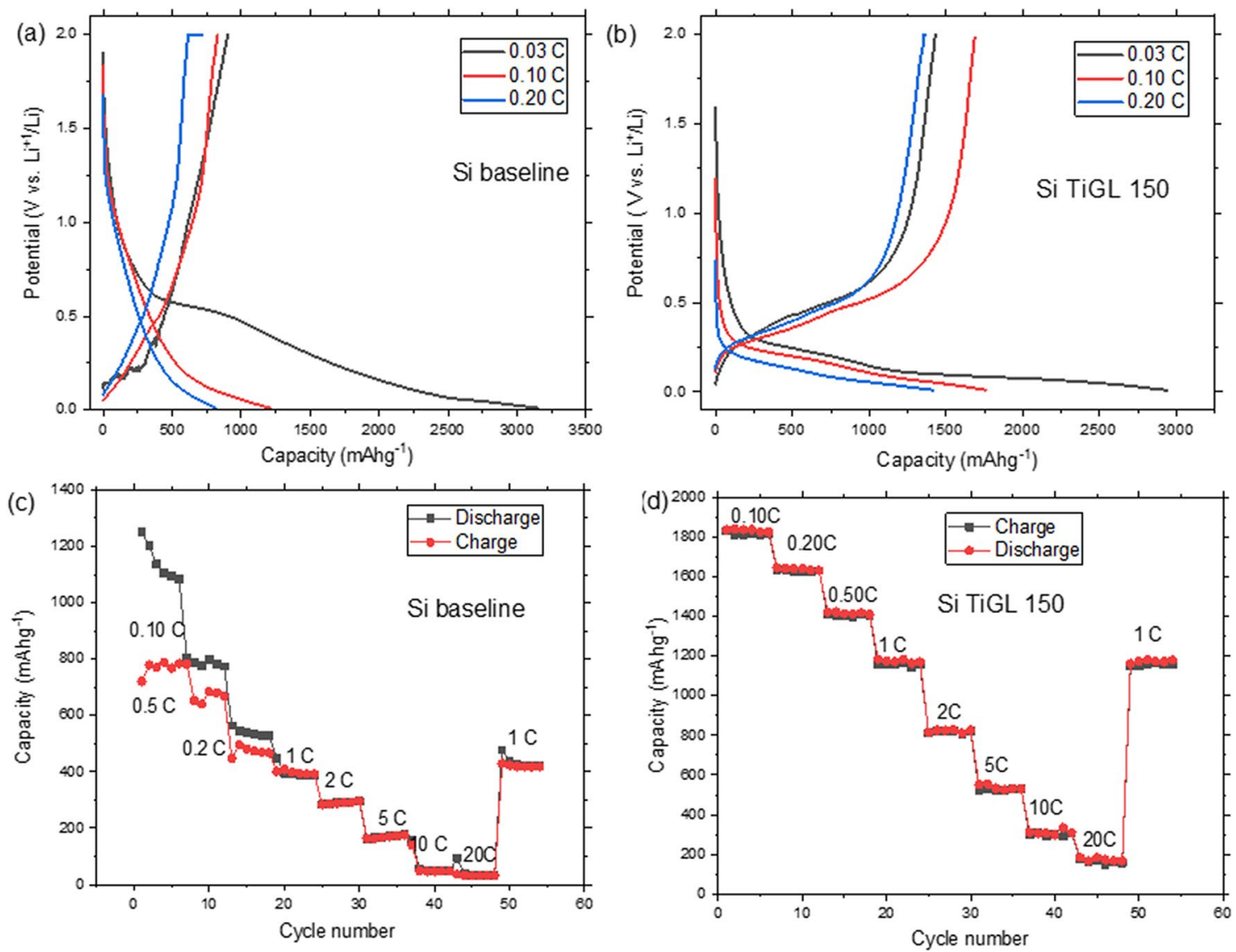

Figure 3. Electrochemical tests (a) and (b) charge/discharge profiles and (c) and (d) rate-capability tests for $\mathrm{Si}$ baseline and Si TiGL 150, respectively.
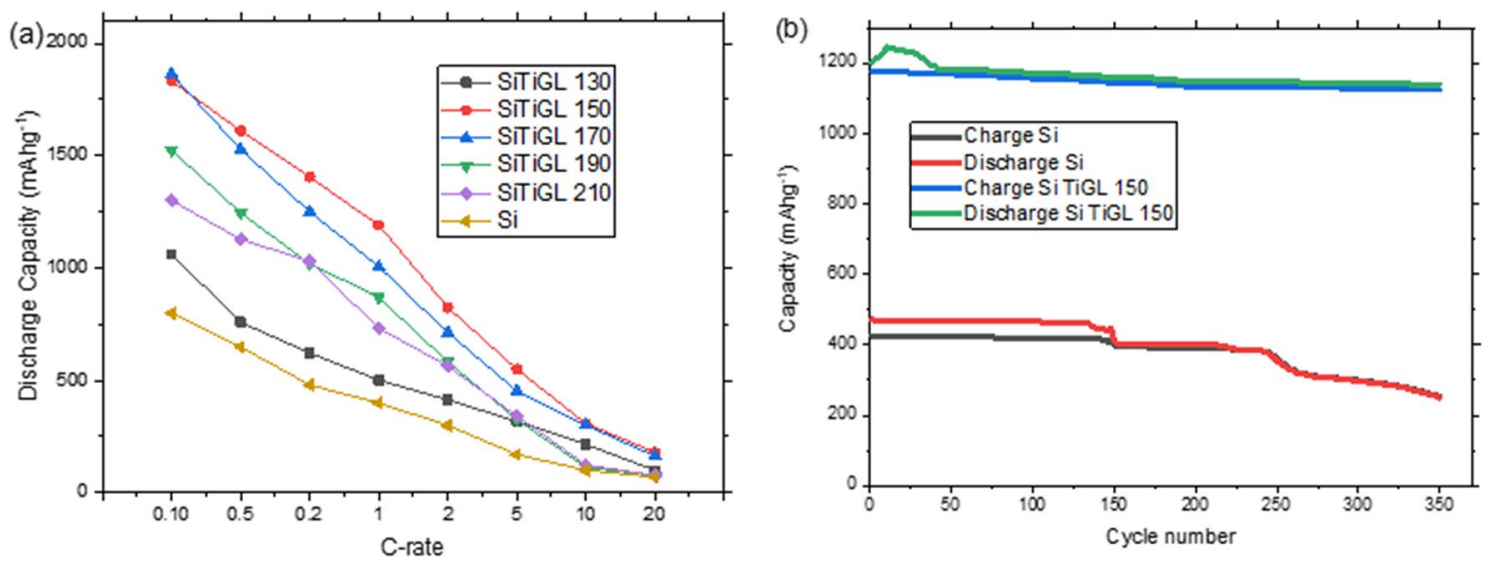

Figure 4. Electrochemical tests (a) C-rate test for all samples and (b) capacity retention measured at $1 \mathrm{C}$ for $\mathrm{Si}$ baseline and Si TiGL 150.

spreading around battery industry as an efficient method working at sufficiently low temperatures to satisfy the integration requirements while maintaining reasonable throughput and cost. Here, the optimized electrode delivers $1800 \mathrm{mAh} \mathrm{g}^{-1}$ at $0.1 \mathrm{C}$ and $500 \mathrm{mAh} \mathrm{g}^{-1}$ at $5 \mathrm{C}$, representing a substantial improvement compared to Si-based electrodes based on nano-metric powders. Moreover, the optimized TiGL coated Si electrode shows an outstanding capacity of $1200 \mathrm{mAh} \mathrm{g}^{-1}$ at $1 \mathrm{C}$ for 350 cycles with capacity retention of $93 \%$. The performance enhancement is directly correlated to the coating layer which acts as an interface modifier by improving efficiencies, discharge capacities and cycling stability. The coating layer boosts the electrical conductivity and lithium kinetics for diffusion by four orders of magnitude, leading to discharge capacities of 300 and $150 \mathrm{mAh} \mathrm{g}^{-1}$ at 10 $\mathrm{C}$ and $20 \mathrm{C}$ rates, respectively. 

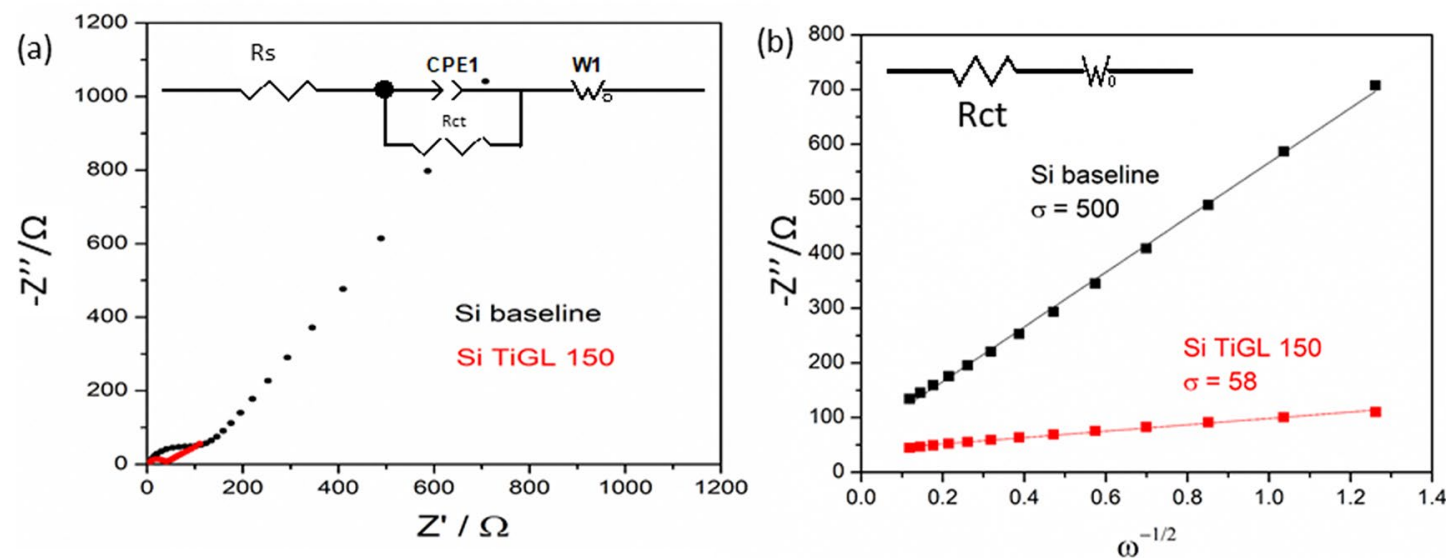

(c)
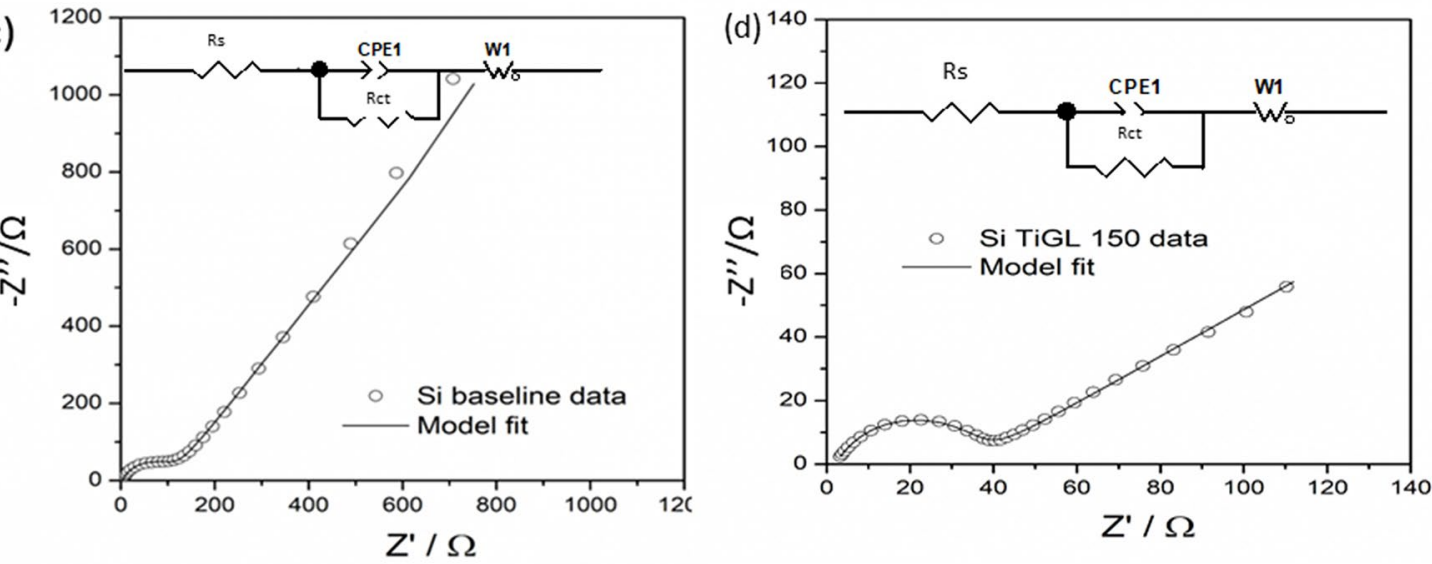

Figure 5. Impedance data presented in the form (a) Nyquist plots, (b) $\mathrm{Z}^{\prime}$ vs $\omega^{-0.5}$ plots and fitting results using Randles circuit inset, and Si baseline and Si TiGL 150 data fitting using the equivalent circuit inset in (c) and (d), after activation respectively.

\section{Methods}

Electrode preparation. Si nanoparticles (Alfa Aesar), Super P carbon black (TIMCAL) and polyvinylidene fluoride PVDF binder (Kynar HSV 900) were dried under vacuum overnight prior slurry formulation. PVDF and carbon black were first milled for $5 \mathrm{~min}$ and then dispersed uniformly in $N$-methyl-2-pyrrolidone (NMP) (99.5\% Sigma Aldrich) by magnetic stirring, after that $\mathrm{Si}$ was added and the mixture stirred for $24 \mathrm{~h}$ to form a slurry. The slurry mass ratio was $60 \mathrm{wt} \%$ of Si NPs, $30 \mathrm{wt} \%$ carbon black, and $10 \mathrm{wt} \%$ PVDF. The final slurry was then casted onto a thin copper foil, using the doctor blade technique. After that, the electrodes were dried under vacuum at $80^{\circ}$ and then pressed at 7 tons.

ALD/MLD. $\quad \mathrm{TiCl}_{4}$ (98\% pure, Strem Chemicals Inc., U.S.A.), and glycerol (GL) (99.5\% pure, Sigma-Aldrich, U.S.A.) were used as precursor and reactant, respectively, for electrode coating. $\mathrm{TiCl}_{4}$ was handled in a glovebox because of its air and moisture sensitivity. $\mathrm{TiCl}_{4}$ bottle was used at room temperature during the ALD/MLD process. The GL vessel was heated up to $60{ }^{\circ} \mathrm{C}$. Nitrogen $\left(\mathrm{N}_{2}\right)$ gas stream entrained the GL by flowing over the headspace in the GL vessel. Ultra-high purity grade $\mathrm{N}_{2}$ (99.999\% pure, Airgas, CO, U.S.A.) was used to purge and carrier gas in the reactor. The ALD reactor used was ASM Microchemistry model F-120. The reactor base pressure was 1 Torr at an $\mathrm{N}_{2}$ gas flow rate of $100 \mathrm{sccm}$. The reactant pulse and $\mathrm{N}_{2}$ purge timing are designated as $(\mathrm{t} 1, \mathrm{t} 2, \mathrm{t} 3, \mathrm{t} 4)$ where $\mathrm{t} 1$ is the $\mathrm{TiCl}_{4}$ exposure time, $\mathrm{t} 2$ is the purge after the $\mathrm{TiCl}_{4}$ exposure, $\mathrm{t} 3$ is the GL dose times, and $t 4$ is the purge time after the GL exposures. The timing sequences were $(3,30,3,30 \mathrm{~s})$, respectively, and the substrate was heated to different temperatures of $130^{\circ} \mathrm{C}, 150^{\circ} \mathrm{C}, 170{ }^{\circ} \mathrm{C}, 190^{\circ} \mathrm{C}$, and $210^{\circ} \mathrm{C}$. The process was repeated 100 times. Si electrodes with dimensions of $4 \mathrm{~cm} \times 4 \mathrm{~cm}$ were used as a substrate. Table S1 in SI summarizes synthesis conditions for the samples and their nomenclature. In the paper, silicon coated samples are refereed as Si TiGL with their heating temperature e.g. Si TiGL 150.

Cell assembly. Coin-type CR2032 cells were assembled in an Ar-filled glove box using a Li metal foil as a counter/reference electrode and the Si based electrodes as the working electrode. The electrolyte was $1 \mathrm{M} \mathrm{LiPF}_{6}$ dissolved in a 1:1 (volume ratio) mixture of ethylene carbonate (EC) and diethyl carbonate (DEC), the separator was a glass micro-filter (Whatman GF/F). The total mass loading of the active material in the electrode of diameter $14 \mathrm{~mm}$ was $1.3 \mathrm{mg}$. 
Characterization. X-ray diffraction (XRD) measurements were performed on a PANalytical X'Pert Pro MPD powder diffractometer with a $\mathrm{Cu}$ Ka X-ray source $(\lambda=0.154 \mathrm{~nm})$. Scanning electron microscopy (SEM) images, along with energy-dispersive X-ray spectroscopy (EDX) measurements, were acquired using a JEOL model JSM-7500FA which was operated at 3 or $5 \mathrm{keV}$. The Transmission electron microscopy (TEM) used for the analysis was a JEOL JEM-2200FS and operated at $200 \mathrm{keV}$. A Fourier transform infrared (FTIR) ALPHA II Fourier-transform infrared (FTIR) spectrometer from Bruker was employed for infrared spectroscopy which was equipped with an Attenuated Total Reflection (ATR) module. The spectra were taken from 4000 to $400 \mathrm{~cm}^{-1}$ in absorbance mode. The electronic conductivity of electrodes was measured using a Jandel RM 3000 four points probe using currents between -5 and $5 \mu \mathrm{A}$. For all these techniques, samples were transferred using a special sample holder that maintains vacuum conditions. In other words, the samples were not exposed to the atmosphere.

Electrochemical measurement. Galvanostatic cycling was performed using a Neware BTS90000 Channel battery tester in the voltage range $0.1-2 \mathrm{~V}$ vs. $\mathrm{Li} / \mathrm{Li}^{+}$at different $\mathrm{C}$-rates $(0.10,0.5,0.2,1,2,5,10$ and $20 \mathrm{C})$ assuming $1 \mathrm{C}=3579 \mathrm{mAh} \mathrm{g}^{-1}$. Prior rate-capability and capacity retention tests, electrodes were activated at 0.03 $\mathrm{C}$ for 2 cycle. Potentiostatic Electrochemical impedance spectroscopy (PEIS) measurements were conducted in the frequency range $20 \mathrm{kHz}-0.1 \mathrm{~Hz}$ with an amplitude of $10 \mathrm{mV}$ for the activated cells at $50 \%$ State of Charge (SOC). Impedance data was fitted to an equivalent circuit using the ZVIEW software.

Received: 10 September 2021; Accepted: 6 December 2021

Published online: 07 January 2022

\section{References}

1. Betz, J. et al. Theoretical versus practical energy: A plea for more transparency in the energy calculation of different rechargeable battery systems. Adv. Energy Mater. 9, 1-18 (2019).

2. Tidblad, A. A. et al. Future material developments for electric vehicle battery cells answering growing demands from an end-user perspective. Energies 14, 4223 (2021).

3. Obrovac, M. N. \& Krause, L. J. Reversible cycling of crystalline silicon powder. J. Electrochem. Soc. 154, A103 (2006).

4. Song, X., Wang, X., Sun, Z., Zhang, P., \& Gao, L.. Recent developments in silicon anode materials for high performance lithium-ion batteries.

5. Bärmann, P. et al. Impact of the crystalline $\mathrm{Li}_{15} \mathrm{Si}_{4}$ phase on the self-discharge mechanism of silicon negative electrodes in organic electrolytes. ACS Appl. Mater. Interfaces 12, 55903-55912 (2020).

6. Kasavajjula, U., Wang, C. \& Appleby, A. J. Nano- and bulk-silicon-based insertion anodes for lithium-ion secondary cells. J. Power Sources 163, 1003-1039 (2007).

7. Casimir, A. et al. Silicon-based anodes for lithium-ion batteries: Effectiveness of materials synthesis and electrode preparation. Nano Energy 27, 359-376 (2016).

8. Gu, M., He, Y., Zheng, J. \& Wang, C. Nanoscale silicon as anode for Li-ion batteries: The fundamentals, promises, and challenges. Nano Energy 17, 366-383 (2015).

9. Liu, X. H. et al. Size-dependent fracture of silicon nanoparticles during lithiation. ACS Nano 6, 1522-1531 (2012).

10. Preman, A. N. et al. Progress of 3D network binders in silicon anodes for lithium ion batteries. J. Mater. Chem. A 8, 25548-25570 (2020).

11. Chen, X. et al. Conductive rigid skeleton supported silicon as high-performance Li-Ion battery anodes. Nano Lett. 12, 4124-4130 (2012).

12. Chockla, A. M. et al. Silicon nanowire fabric as a lithium ion battery electrode material. J. Am. Chem. Soc. 133, 20914-20921 (2011).

13. Park, M. H. et al. Silicon nanotube battery anodes. Nano Lett. 9, 3844-3847 (2009).

14. Phadatare, M. et al. Silicon-nanographite aerogel-based anodes for high performance lithium ion batteries. Sci. Rep. 9, 1-9 (2019).

15. Alaboina, P. K., Cho, J. S., Uddin, M. J. \& Cho, S. J. Mechanically prelithiated silicon nano alloy as highly engineered anode material. Electrochim. Acta 258, 623-630 (2017).

16. Meng, X. An overview of molecular layer deposition for organic and organic-inorganic hybrid materials: Mechanisms, growth characteristics, and promising applications. J. Mater. Chem. A 5, 18326-18378 (2017).

17. Abdulagatov, A. I. et al. Molecular layer deposition of titanicone films using TiCl 4 and ethylene glycol or glycerol: Growth and properties. Chem. Mater. 24, 2854-2863 (2012).

18. Piper, D. M. et al. Reversible high-capacity Si nanocomposite anodes for lithium-ion batteries enabled by molecular layer deposition. Adv. Mater. 26, 1596-1601 (2014).

19. $\mathrm{Mu}$, T. et al. Stable silicon anodes by molecular layer deposited artificial zincone coatings. Adv. Funct. Mater. 31, 1-9 (2021).

20. Yoon, B., Seghete, D. S., Cavanagh, A. \& George, M. S. Molecular layer deposition of hybrid organic-inorganic alucone polymer films using a three-step ABC reaction sequence. Chem. Mater. 21, 5365-5374 (2009).

21. Sundberg, P. \& Karppinen, M. Organic and inorganic-organic thin film structures by molecular layer deposition: A review. Beilstein J. Nanotechnol. 5123(5), 1104-1136 (2014).

22. Adamczyk, M. N., Dameron, A. \& George, M. S. Molecular layer deposition of poly(p-phenylene terephthalamide) films using terephthaloyl chloride and p-phenylenediamine. Langmuir 24, 2081-2089 (2008).

23. Jiao, X. W., Tian, Y. H. \& Zhang, X. J. Hollow Si nanospheres with amorphous TiO2 layer used as anode for high-performance Li-ion battery. Appl. Surf. Sci. 566, 150682 (2021).

24. Qiao, L., Yang, Z., Li, X. \& He, D. Improvement of electrochemical performances of ultrathin Ti-coated Si-based multilayer nanofibers as anode materials for lithium-ion batteries. Surf. Coat. Technol. 424, 127669 (2021).

25. Zhu, H. et al. Molecular-layer-deposited tincone: A new hybrid organic-inorganic anode material for three-dimensional microbatteries. Chem. Commun. 56, 13221-13224 (2020).

26. Van De Kerckhove, K. et al. Molecular layer deposition of 'titanicone', a titanium-based hybrid material, as an electrode for lithiumion batteries. Dalt. Trans. 45, 1176-1184 (2016).

27. Dameron, A. A. et al. Molecular layer deposition of alucone polymer films using trimethylaluminum and ethylene glycol. Chem. Mater. 20, 3315-3326 (2008). 
28. Zhu, G., Wang, Y., Yang, S., Qu, Q. \& Zheng, H. Correlation between the physical parameters and the electrochemical performance of a silicon anode in lithium-ion batteries. J. Mater. 5, 164-175 (2019).

29. Keller, C. et al. Effect of size and shape on electrochemical performance of nano-silicon-based lithium battery. Nanomaterials 11, 1-15 (2021).

30. Zhou, Q., Liu, J., Gong, X. \& Wang, Z. A flexible and conductive connection introduced by cross-linked CNTs between submicron Si@C particles for better performance LIB anode†. Nanosc. Adv. https://doi.org/10.1039/d1na00012h (2021).

31. Luo, J. et al. Crumpled graphene-encapsulated Si nanoparticles for lithium ion battery anodes. J. Phys. Chem. Lett. 3, 1824-1829 (2012).

32. Zhou, M. et al. High-performance silicon battery anodes enabled by engineering graphene assemblies. Nano Lett. 15, 6222-6228 (2015).

33. Scribner Associates. Zview version 3.2b, www.scribner.com.

34. Ding, N. et al. Determination of the diffusion coefficient of lithium ions in nano-Si. Solid State Ion. 180, 222-225 (2009).

35. Wu, H. et al. Stable cycling of double-walled silicon nanotube battery anodes through solid-electrolyte interphase control. Nat. Nanotechnol. 7, 25 (2012).

36. Karuppiah, S. et al. A scalable silicon nanowires-grown-on-graphite composite for high-energy lithium batteries. ACS Nano 14, 12006-12015 (2020).

\section{Acknowledgements}

Funding from the European Comission and Tecnio Spring under the Grant agreement TECSPR18-1-0049 Towards High Energy All Solid State Lithium Batteries (SOLBAT) is gratefully acknowledged. IREC acknowledges support of Generalitat de Catalunya. The authors like to acknowledge the support of Aalto University.

\section{Author contributions}

Z.C.H and D.S.R. conceived the experiment(s), Z.C.H and D.S.R. conducted the experiment(s), C.F., J.J.B, J.R.M. and T.K. analyzed the results. All authors reviewed the manuscript.

\section{Competing interests}

The authors declare no competing interests.

\section{Additional information}

Supplementary Information The online version contains supplementary material available at https://doi.org/ 10.1038/s41598-021-04105-x.

Correspondence and requests for materials should be addressed to T.K. or J.J.B.

Reprints and permissions information is available at www.nature.com/reprints.

Publisher's note Springer Nature remains neutral with regard to jurisdictional claims in published maps and institutional affiliations.

(c) Open Access This article is licensed under a Creative Commons Attribution 4.0 International

License, which permits use, sharing, adaptation, distribution and reproduction in any medium or format, as long as you give appropriate credit to the original author(s) and the source, provide a link to the Creative Commons licence, and indicate if changes were made. The images or other third party material in this article are included in the article's Creative Commons licence, unless indicated otherwise in a credit line to the material. If material is not included in the article's Creative Commons licence and your intended use is not permitted by statutory regulation or exceeds the permitted use, you will need to obtain permission directly from the copyright holder. To view a copy of this licence, visit http://creativecommons.org/licenses/by/4.0/.

(c) The Author(s) 2022 